\title{
Raised human cartilage glycoprotein-39 plasma levels in patients with rheumatoid arthritis and other inflammatory conditions
}

K Vos, P Steenbakkers, A M M Miltenburg, E Bos, M W van den Heuvel, R A van Hogezand, R R P de Vries, F C Breedveld, A M H Boots

\begin{abstract}
Objective-To evaluate plasma human cartilage glycoprotein (HC gp-39) as a possible marker for the presence and/or activity of rheumatoid arthritis (RA) and other inflammatory conditions.

Background-HC gp-39 is a secretory product of chondrocytes, synovial cells, macrophages, and neutrophils. HC gp-39, also described as YKL-40, was found to be a marker of joint disease and tissue injury in RA and various other diseases.

Methods-Levels of HC gp-39 were determined by a sandwich enzyme linked immunosorbent assay (ELISA) in 47 patients with RA, 47 with osteoarthritis (OA), 24 with systemic lupus erythematosus (SLE), 24 with inflammatory bowel disease (IBD), and in 47 healthy controls. A disease activity score was assessed in the patients with RA, SLE, and IBD.
\end{abstract}

Department of Rheumatology, LUMC, Leiden, The Netherlands K Vos

F C Breedveld

Department of Immunohaematology and Blood Bank, LUMC, Leiden R R P de Vries

Department of Hepato-

gastroenterology, LUMC, Leiden

R A van Hogezand

Department of Pharmacology, Section Immunology, NV Organon, Oss

P Steenbakkers

A M M Miltenburg

E Bos

A M H Boots

QA/Statistical Department, NV Organon, Oss $\mathrm{M}$ W van den Heuvel

Correspondence to: Dr K Vos, Department of Rheumatology, Leiden University Medical Centre, PO Box 9600, 2300 RC Leiden, The Netherlands Email:

kvos@rheumatology.azl.nl

Accepted for publication 24 January 2000 the finding that $\mathrm{HC}$ gp-39 messenger RNA is expressed in cartilage obtained from patients with RA, whereas healthy adult cartilage did not contain this transcript. ${ }^{1}$ Further interest in the glycoprotein was prompted by the predominant recognition of HC gp-39 derived peptides, selected for their ability to bind to RA associated DR4 (DRB $\left.1^{\star} 0401\right)$ molecules, by peripheral blood $\mathrm{T}$ cells from patients with RA. ${ }^{2}$ Moreover, it has been shown that HC gp-39 emulsified in complete Freund's adjuvant induced arthritis in $\mathrm{BALB} / \mathrm{c}$ mice. This arthritis was suppressed by intranasal administration of HC gp-39 before immunisation, ${ }^{2}$ suggesting that immunological tolerance of the protein may control disease activity.

The function of the glycoprotein at present is unknown. HC gp-39 shows homology with the chitinase protein family, but no chitinase activity has been found. ${ }^{156}$ The glycoprotein has also been described as YKL-40. ${ }^{7-13}$ Levels of HC gp-39 have been determined in serum and synovial fluid (SF) of patients with arthropathies. ${ }^{81012}{ }^{14} \mathrm{HC}$ gp-39 serum levels in patients with joint disease were significantly higher than those found in healthy controls. ${ }^{8}$ In this study the patient group with joint disease comprised patients with RA, osteoarthritis (OA), crystal arthritis, reactive arthritis, and undifferentiated monarthritis. The serum HC gp-39 concentrations did not differ significantly between patients with inflammatory joint disease and those with OA. HC gp-39 levels in SF of patients with inflammatory or degenerative joint diseases were 10-15-fold higher than serum levels and a correlation was found between HC gp-39 concentration in SF and serum. These findings suggest that a substantial portion of serum HC gp-39 originates from the joint. HC gp-39 levels in serum and SF strongly correlated with serum $\mathrm{C}$ reactive protein (CRP) and SF interleukin $6 .{ }^{8}$ In a later study it was shown that serum HC gp-39 levels in patients with active RA (56 patients) and the levels in patients with OA (27) were significantly higher than in patients with inactive RA (9), patients with diabetes (35), and healthy controls (329). ${ }^{14}$ No differences in HC gp-39 levels were seen between patients with active RA and patients with OA. In this study no information was given on disease variables of the RA patient group. In a recent study the HC gp-39 levels in patients with RA with clinically and biochemically active disease were significantly higher than in healthy controls and patients with RA with low disease activity. $^{12}$

Apart from studies in RA and OA, no data have been published on the level of HC gp-39 
Table 1 Clinical and demographic characteristics of the subjects investigated

\begin{tabular}{llllll}
\hline & $R A^{\star}(n=50)$ & $O A^{\star}(n=51)$ & $I B D^{\star}(n=26)$ & $S L E^{\star}(n=24)$ & $H C^{\star}(n=49)$ \\
\hline Age median (years) & 65.0 & 66.0 & 34.0 & 38.0 & 44.0 \\
Women (No (\%)) & $33(66)$ & $41(80)$ & $17(65)$ & $22(92)$ & $21(43)$ \\
Disease established median (years) & 7.5 & 3.5 & 5.0 & 4.0 & $\mathrm{NA}^{\star}$ \\
\hline
\end{tabular}

$\mathrm{RA}=$ rheumatoid arthritis; $\mathrm{OA}=$ osteoarthritis; $\mathrm{IBD}=$ inflammatory bowel disease; $\mathrm{SLE}=$ systemic lupus erythematosus; $\mathrm{HC}=$ healthy control; NA = not applicable

Table 2 Disease characteristics of 50 patients with $R A$

Characteristics

Rheumatoid factor positive (\%)

Rheumatoid factor IgM (IU/ml, median)

Erosive disease (\%)

Nodular disease $(\%)$

$\mathrm{ESR}^{\star}(\mathrm{mm} / 1 \mathrm{st} \mathrm{h}$, median)

Tender joint score (median)

Swollen joint score (median)

Patient's assessment score (VAS ${ }^{\star}$, median)

Doctor's assessment score (VAS, median)

Modified disease activity score (DAS)

${ }^{\star} \mathrm{ESR}=$ erythrocyte sedimentation rate; VAS = visual analogue scale.

(YKL-40) in chronic inflammatory diseases. To evaluate HC gp-39 as a marker associated with inflammatory processes, with and without joint disease, plasma HC gp-39 levels were measured in patients with RA, primary OA, SLE, IBD, and in healthy controls. In the RA, SLE, and IBD patient groups a correlation between disease activity variables and plasma HC gp-39 levels was determined.

\section{Patients and methods}

PATIENTS

Patients with RA (50), OA (51), SLE (24), IBD (26), and healthy controls (49) participated in the study. The patients were visiting the outpatients clinic of the departments of rheumatology and hepatogastroenterology of the Leiden University Medical Centre. The healthy controls were blood donors visiting the regional blood bank Leidschenhage.

The patients with RA fulfilled the American College of Rheumatology criteria. ${ }^{15}$ Disease duration varied from one to 56 years. Patients who were treated with more than $20 \mathrm{mg}$ prednisone, cyclosporin, or any experimental treatment were excluded. Disease activity was measured by assessment of 28 joints for tenderness and swelling, assessment of disease activity on a visual analogue scale (VAS) by the patient and the doctor, and by measuring the erythrocyte sedimentation rate (ESR, Westergren method). Extra-articular manifestations were documented and the serum IgM rheumatoid factor was measured by enzyme linked immunosorbent assay (ELISA). A modified disease activity score (DAS) was calculated: $(0.53938 \times \sqrt{ }$ (number of tender joints) $)+$ $(0.06465 \times$ number of swollen joints $)+(0.330$ $\times \ln$ ESR) $+0.224 .{ }^{16}{ }^{17}$

In the OA group only patients with primary OA were included. It was noted whether the OA was localised (two areas or fewer) or generalised (three or more areas).

The patients with SLE fulfilled four or more of the 11 criteria for classification of SLE. ${ }^{18}$ Disease activity was measured by assessment of the SLE disease activity index (SLEDAI). ${ }^{19}$
The patient group with IBD consisted of patients with active ulcerative colitis or Crohn's disease. These patients had no arthritis. All patients with ulcerative colitis had rectal bleeding and diarrhoea, whereas the patients with Crohn's disease had a disease activity index (CDAI) of 150 or more. ${ }^{20}$ The CDAI included variables such as the number of stools, rating of abdominal pain, rating of general wellbeing, and symptoms such as fistulas, anal fissures, skin lesions, and fever.

PREPARATION OF SAMPLES

After the patient's informed consent had been obtained, peripheral blood samples were collected in heparin coated tubes between $900 \mathrm{am}$ and $100 \mathrm{pm}$. Plasma samples were stored at $-20^{\circ} \mathrm{C}$ until use for the determination of $\mathrm{HC}$ gp-39 levels.

\section{MONOCLONAL ANTIBODIES}

Balb/c mice were immunised with HC gp-39 purified from cell culture supernatant of MG63 cells emulsified in complete Freund's adjuvant (1:1). After serum conversion as determined by ELISA, spleen cells were fused with NS1 cells through electrofusion. Clone selection was carried out by ELISA and selections were confirmed by western blot analysis on culture supernatants containing HC gp-39, and by Biacore experiments. Monoclonal antibody (MoAb) 8B was an excellent reagent in western blot, probably recognising a linear epitope of HC gp-39, whereas MoAb 10B is directed against a conformational epitope distant from that of MoAb 8B (determined by Biacore analysis) (data not shown).

HC GP-39 ELISA

Polystyrene micro-ELISA strip-plates (Greiner) were coated overnight at $4^{\circ} \mathrm{C}$ with $100 \mu \mathrm{l} /$ well of $1 \mu \mathrm{g} / \mathrm{ml}$ anti-HC gp-39 capture antibody (HC gp-39 8B) in phosphate buffered saline (PBS). The supernatant was discarded and the wells were incubated for one hour at room temperature with $200 \mu \mathrm{l} \mathrm{PBS,} 0.05 \%$ Tween 20 (PBST) to block excess free binding sites. Subsequently, plates were washed three times with PBST and incubated for one hour at room temperature with $100 \mu$ of sample or recombinant HC gp-39 standard in PBST. Plasma samples were diluted $1: 2$ or $1: 4$ in PBST. After this incubation the plates were washed three times with PBST and incubated for one hour at room temperature with horseradish peroxidase labelled anti-HC gp-39 detection antibody (HC gp-39 10B) at a dilution of 1:1000 in PBST. Then, plates were washed three times with PBST and three times with demi-water. Finally, the colour reaction was developed by incubating the wells with 100 
Table 3 Descriptive statistics of human cartilage glycoprotein-39 plasma levels in the different groups

\begin{tabular}{llllll}
\hline Subject groups & No & Geometric mean $(\mathrm{ng} / \mathrm{ml})$ & $R S D^{\star}(\%)$ & Median $(\mathrm{ng} / \mathrm{ml})$ & Duncant grouping \\
\hline $\mathrm{RA}^{\star}$ & 47 & 38.3 & 112.3 & 31.0 & $\mathrm{~A}$ \\
IBD $^{\star}$ & 24 & 24.8 & 72.0 & 22.5 & $\mathrm{~B}$ \\
$\mathrm{OA}^{\star}$ & 47 & 24.7 & 76.6 & 20.6 & $\mathrm{~B}$ \\
SLE $^{\star}$ & 24 & 22.6 & 95.2 & 21.1 & $\mathrm{~B}$ \\
$\mathrm{HC}^{\star}$ & 47 & 15.5 & 42.0 & 14.8 & $\mathrm{C}$ \\
\hline
\end{tabular}

${ }^{\star} \mathrm{HC}=$ healthy control; RSD = relative standard deviation; $\mathrm{RA}=$ rheumatoid arthritis; $\mathrm{IBD}=$ inflammatory bowel disease; $\mathrm{OA}=$ osteoarthritis; SLE = systemic lupus erythematosus.

†Duncan grouping (Duncan's multiple range test): means with the same letter are not significantly different $(p>0.05)$; means with different letters differ significantly $(\mathrm{p} \leqslant 0.05)$.

$\mu$ tetramethylbenzidine/ureum peroxide substrate solution (Organon Teknika). ${ }^{21}$ The enzyme reaction was stopped by addition of $100 \mu 12 \mathrm{M} \mathrm{H}_{2} \mathrm{SO}_{4}$ to each well. Optical density at $450 \mathrm{~nm}$ was measured with a microtitre plate reader, and HC gp-39 concentrations were determined with Prism (Graph Pad) software. Recombinant HC gp-39 standard curves were drawn from 0 to $300 \mathrm{ng} / \mathrm{ml}$. Because it has been shown that heparin binds HC gp- $39^{4}$ and the blood samples were collected in heparin tubes, the measured levels of HC gp-39 in this study may be an underestimation. The ELISA has a lower detection limit of 13 pg of HC gp-39, corresponding to $130 \mathrm{pg} / \mathrm{ml}$, an intra-assay variation of $<5 \%$, and a total assay variation of $18 \%$. The yield was $99 \%$.

\section{STATISTICAL ANALYSIS}

To compare HC gp-39 plasma levels between the patient groups and the healthy control group, levels were analysed with a one way analysis of variance (ANOVA) on the logarithmically transformed levels, followed by Duncan's multiple range test $(\alpha=0.05)$. Correlation

Table 4 Relation between the level of human cartilage glycoprotein-39 and clinical variables in patients with rheumatoid arthritis

\begin{tabular}{lcc}
\hline Diagnostic variable & Spearman correlation coefficient & p Value \\
\hline Years since first symptoms & 0.045 & 0.770 \\
Years since disease established & -0.088 & 0.558 \\
IgM rheumatoid factor $(\mathrm{IU} / \mathrm{ml})$ & 0.440 & $\mathbf{0 . 0 0 7}$ \\
Tender joint count & 0.084 & 0.574 \\
Swollen joint count & 0.149 & 0.318 \\
ESR $^{\star}(\mathrm{mm} / 1$ st h) & 0.396 & $\mathbf{0 . 0 0 6}$ \\
DAS & 0.250 & 0.094 \\
\hline
\end{tabular}

^ESR = erythrocyte sedimentation rate; DAS = disease activity score.

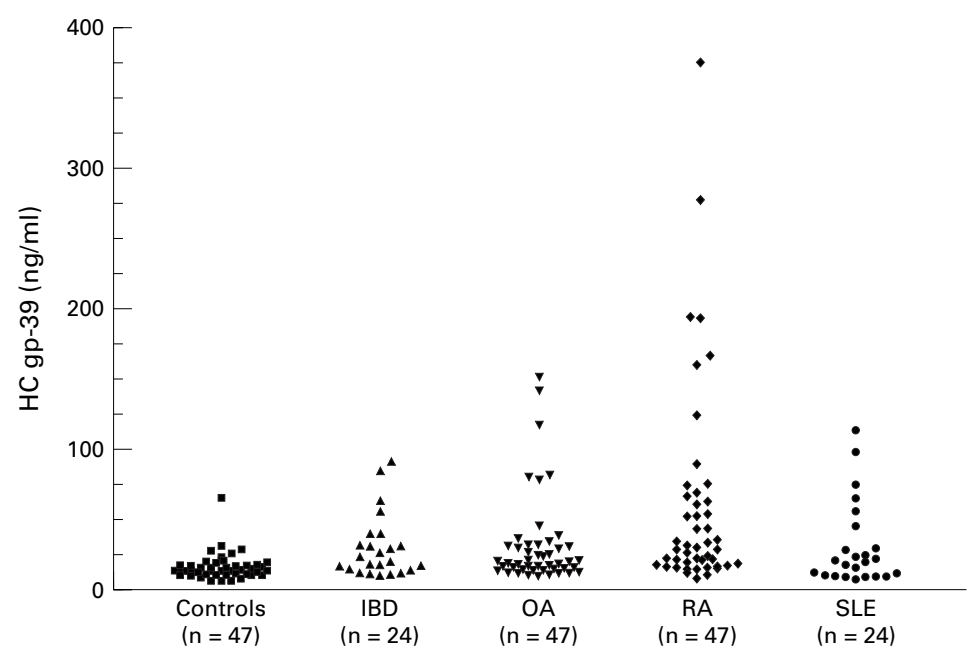

Figure 1 Human cartilage glycoprotein-39 (HC gp-39) levels in different patient groups. $I B D=$ inflammatory bowel disease; $O A=$ osteoarthritis; $R A=$ rheumatoid arthritis; SLE = systemic lupus erythematosus. coefficients were calculated and tested using Spearman's rank order correlation test (two sided, $\alpha=0.05)$.

\section{Results}

Table 1 summarises the demographic and clinical characteristics of the different patient groups and healthy controls. Table 2 gives the disease characteristics of the RA patient group. It can be concluded that the RA patient group is a typical cross section of the RA population visiting the outpatients clinic of a tertial referral centre. The RA patient group was a heterogeneous group with respect to disease characteristics: the duration of disease varied from 1 to 56 years, the swollen joint count from 1 to 22 , the tender joint count from 0 to 20 , and the ESR from 2 to $89 \mathrm{~mm} / 1 \mathrm{st} \mathrm{h}$. The clinical variables of the patients with SLE, of whom $87.5 \%$ had a history of arthritis, also varied considerably: the duration of disease varied from 1 to 18 years and the SLEDAI varied from 0 to 24 . For patients with IBD, the disease duration varied from 2 to 31 years. In the latter patient group a disease activity score index (CDAI) was measured only for the 13 patients with Crohn's disease; this varied from 106 to 366 (one patient with a CDAI below 150 (106) was mistakenly included). In the OA patient group most patients had localised OA (71\%).

Table 3 gives the HC gp-39 plasma levels for the various groups (for 11 subjects-three patients with RA, four patients with OA, two patients with IBD, and two healthy controlsthe levels could not be reported). HC gp-39 plasma levels differed significantly between patient groups and the control group (ANOVA, $p=0.0001$ ) (table 3, fig 1). From Duncan's test it was found that the mean of the HC gp-39 plasma levels in the RA group was significantly higher than the means found in the other patient groups and the healthy control group (table $3, p \leqslant 0.05$ ). The means of the HC gp-39 plasma levels in the OA, SLE, and IBD patient groups were also significantly higher than that of the healthy control group $(p \leqslant 0.05)$. No significant difference was observed between the mean plasma levels of $\mathrm{HC}$ gp-39 between the OA, SLE, and IBD patient groups (table 3 ).

Within the group of patients with RA a significant positive correlation was found between the level of HC gp-39 and the ESR $(p=0.006)$, and between HC gp-39 and the IgM rheumatoid factor level $(\mathrm{p}=0.007)$ (table 4). There was no correlation with other clinical variables, such as the duration of symptoms of disease, the presence of extra- 
articular manifestations, the radiological stage of disease, the swollen or tender joint count, or the DAS. In the SLE and IBD patient groups the level of HC gp-39 did not correlate with any of the disease activity variables (SLEDAI and CDAI (for Crohn's disease) respectively, plus disease duration) measured.

\section{Discussion}

The present study shows that serum levels of HC gp-39 in patients with RA are significantly higher than those in healthy controls. This finding is in agreement with previous studies that also showed raised levels of HC gp-39 in patients with arthritis. ${ }^{81214}$ This study further shows that HC gp-39 levels are raised in OA, SLE, and IBD (compared with healthy controls), though lower levels were found in these conditions than in the RA patient group. It is recognised, in our study, that the patients in the RA and OA group represent a relatively older population with a higher percentage of women than in the healthy control group. Previously, however, no age or sex differences were found in serum HC gp-39 levels in subjects younger than $70,{ }^{10}$ thereby suggesting that these variables are less relevant. Indeed, we did not find a significant correlation between plasma $\mathrm{HC}$ gp-39 levels and age in the RA and OA patient groups.

In contrast with the findings in previous studies, our study shows a difference in HC gp-39 levels for patients with RA and OA. The lower levels found in patients with $\mathrm{OA}$ are thought to be related to the fact that a substantial fraction $(71 \%)$ of patients with OA had localised (two areas or fewer) joint disease.

This study is the first to demonstrate raised levels of HC gp-39 in patients with SLE and IBD. This is in line with previous studies which showed that HC gp-39 levels can be found in conditions not related to RA. In patients with alcoholic cirrhosis a correlation was found between the plasma HC gp-39 level and the degree of liver fibrosis. ${ }^{9}$ In that study it was shown that HC gp-39 is released from the hepatosplanchnic area, providing evidence that the glycoprotein is produced by the liver. Immunohistochemistry showed that HC gp-39 is localised in fibrotic areas of the liver. In addition, raised HC gp-39 levels were found in patients with recurrent breast cancer and colorectal cancer, where the protein proved to be a prognostic marker for short survival. ${ }^{7}{ }^{13}$ More recently, it has been shown that diabetic patients have increased levels of HC gp-39. ${ }^{14}$ Our present observations further add to the view that the glycoprotein is not joint-specific and that it is upregulated in different conditions not necessarily involving the joint.

HC gp-39 levels in patients with RA correlated positively with the ESR and surprisingly also with $\operatorname{IgM} \mathrm{RF}$ level. No correlation, however, was found with clinical variables of disease activity. Further, raised HC gp-39 levels in patients with SLE and IBD did not correlate with disease activity scores. Previously, raised HC gp-39 levels in patients with RA were found to be positively correlated with the ESR, the CRP level, and the joint counts for swelling and pain in patients with RA. ${ }^{12}$ This discrepancy might be attributed to the fact that in our study the age, disease duration, and disease activity of the RA patient group varied considerably. In the study by Harvey et al an increased level of HC gp-39 was found in patients with active RA only, but no details were given about disease activity variables. ${ }^{14}$

HC gp-39 is produced by human synoviocytes, chondrocytes, and by macrophages, neutrophils, and monocytes. ${ }^{1-411}$ Further evidence suggests that HC gp-39 is also expressed by peripheral blood mononuclear cells in patients with RA. ${ }^{20}$ We reasoned that the glycoprotein, whether produced locally at the site of inflammation or systemically, is widely expressed and thus may be a prominent target for specific $\mathrm{T}$ cells. ${ }^{2}$ Such a situation creates possibilities for the development of a specific immunomodulatory treatment. In mouse studies it was shown that intranasal application of the protein suppressed inflammation by generation of $\mathrm{HC}$ gp-39 specific modulatory $\mathrm{T}$ cells, which may then travel to the joints. ${ }^{22}$

The data above support the hypothesis that HC gp-39 is a promising candidate antigen for tolerance induction in RA. The results of the present and previous studies support this hypothesis by finding the highest level of $\mathrm{HC}$ gp-39 expression in patients with RA. It remains to be clarified whether the raised HC gp-39 levels found in other inflammatory conditions are relevant to the autoimmune response underlying the disease process.

The authors are grateful to A de Haan for setting up the ELISA, and $\mathrm{E}$ Rovers and $\mathrm{H}$ Hubers for testing the samples.

1 Hakala BE, White C, Recklies AD. Human cartilage gp-39, a major secretory product of articular chondrocytes and synovial cells, is a mammalian member of a chitinase protein family. J Biol Chem 1993;268:25803-10.

2 Verheijden GF, Rijnders AW, Bos E, Coenen-de Roo CJJ, van Staveren CJ, Miltenburg AM, et al. Human cartilage glycoprotein-39 as a candidate autoantigen in rheumatoid glycoprotein-39 as a candidate autoantigen in
arthritis. Arthritis Rheum 1997;40:1115-25.

3 Kirkpatrick RB, Emery JG, Connor JR, Dodds R, Lysko $\mathrm{PG}$, Rosenberg $M$. Induction and expression of human cartilage glycoprotein 39 in rheumatoid inflammatory and peripheral blood monocyte-derived macrophages. Exp Cell Res 1997;237:46-54.

4 Nyirkos P, Golds EE. Human synovial cells secrete a $39 \mathrm{kDa}$ protein similar to a bovine mammary protein expressed
during the non-lactating period. Biochem J 1990;269: 265-8.

5 Henrissat B, Bairoch A. New families in the classification of glycosyl hydrolases based on amino acid sequence similarities. Biochem J 1993;293:781-8.

$6 \mathrm{Hu} \mathrm{B}$, Trinh K, Figueira WF, Price PA. Isolation and sequence of a novel human chondrocyte protein related to mammalian members of the chitinase protein family. J Biol Chem 1996;271:19415-20.

7 Johansen JS, Cintin C, Jorgensen M, Kamby C, Price PA. Serum YKL-40: a new potential marker of prognosis and cancer. Eur J Cancer 1995;31:1437-42.

8 Johansen JS, Jensen HS, Price PA. A new biochemical marker for joint injury. Analysis of YKL-40 in serum and synovial fluid. Br J Rheumatol 1993;32:949-55.

9 Johansen JS, Moller S, Price PA, Bendtsen F, Junge J, Garbarsch C, et al. Plasma YKL-40: a new potential marker of fibrosis in patients with alcoholic cirrhosis? Scand J Gastroenterol 1997;32:582-90.

10 Johansen JS, Hvolris J, Hansen M, Backer V, Lorenzen I, Price PA. Serum YKL-40 levels in healthy children and adults. Comparison with serum and synovial fluid levels of YKL-40 in patients with osteoarthritis or trauma of the knee joint. Br J Rheumatol 1996;35:553-9.

11 Volck B, Price PA, Johansen JS, Sorensen S, Benfield TL, Nielsen HJ, et al. YKL-40, a mammalian member of the chitinase family, is a matrix protein of specific granules in human neutrophils. Proc Assoc Am Physicians 1998;110: 351-60.

12 Johansen JS, Stoltenberg $M$, Hansen $M$, Florescu A, Horslev-Petersen K, Lorenzen I, et al. Serum YKL-40 con- 
centrations in patients with rheumatoid arthritis: relation to disease activity. Rheumatology 1999;38:618-26.

13 Cintin C, Johansen JS, Christensen IJ, Price PA, Sorensen S, Nielsen HJ. Serum YKL-40 and colorectal cancer. Br J Cancer 1999;79:1494-9.

14 Harvey S, Weisman M, O'Dell J, Scott T, Krusemeier M, Visor J, et al. Chondrex: new marker of joint disease. Clin Chem 1998;44:509-16.

15 Arnett FC, Edworthy SM, Bloch DA, McShane DJ, Fries $\mathrm{JF}$, Cooper NS, et al. The American Rheumatism Association 1987 revised criteria for the classification of rheumatoid arthritis. Arthritis Rheum 1988;31:315-24.

16 van der Heijde DM, van't Hoff MA, van Riel PL, Theunisse LA, Lubberts EW, van Leeuwen MA, et al. Judging disease activity in clinical practice in rheumatoid arthritis: first step in the development of a disease activity score. Ann Rheum Dis 1990;49:916-20.

17 Fuchs HA. The use of the disease activity score in the analysis of clinical trials in rheumatoid arthritis. J Rheumatol 1993;20:1863-6.
18 Tan EM, Cohen AS, Fries JF, Masi AT, McShane DJ, Rothfield NF, et al. The 1982 revised criteria for the classification of systemic

9 Bombardier C, Gladman DD, Urowitz MB, Caron D, Chang CH. Derivation of the SLEDAI. A disease activity index for lupus patients. The Committee on Prognosis Studies in SLE. Arthritis Rheum 1992;35:630-40.

20 Best WR, Becktel JM, Singleton JW, Kern FJ. Development of a Crohn's disease activity index. National Cooperative Crohn's Disease Study. Gastroenterology 1976;70:439-44.

21 Bos ES, van der Doelen AA, van Rooy N, Schuurs AH. $3,3^{\prime}, 5,5^{\prime}$-Tetramethylbenzidine as an Ames test negative chromogen for horse-radish peroxidase in enzymeimmunoassay. J Immunoassay 1981;2:187-204.

22 Wolvers DA, Coenen-de Roo CJJ, Mebius RE, van der Cammen MJ, Tirion F, Miltenburg AM, et al. Intranasally induced $\mathrm{M}$, Tinun $\mathrm{F}$, Miltenburg AM, et al. Intranasally teristics of the draining tymph ne is deterien human cartilage gp-39. J Immunol 1999;162:1994-8. 